\title{
THE THEORY OF INSURANCE RISK PREMIUMS - A RE-EXAMINATION IN THE LIGHT OF RECENT DEVELOPMENTS IN CAPITAL MARKET THEORY
}

\author{
YeHUdA KAHANE *
}

\section{INTRODUCTION}

The premium calculation principle is one of the main objectives of study for actuaries. There seems to be full agreement among the leading theoreticians in the field that the insurance premium should reflect both the expected claims and certain loadings. This is true for policy, risk or portfolio. There are three types of positive loadings: a) a loading to cover commissions, administrative costs and claim-settlement expenses; b) a loading to cover some profit (a cost-plus approach); and c) a loading for the risk taken by the insurer when underwriting the policy. The administrative costs can be considered a part of "expected gross claims". Thus, the insurer's ratemaking decision depends on his ability to estimate expected claims (including costs) and on the selection of a fair risk loading.

The main concern in the literature is the appropriate measurement of the risk and the exact loading formula. BühlmanN [1970, ch. 5] and others identified four possible principles of risk loading, namely, the expected value principle, the standard deviation loading, the variance loading, and the loading according to the principle of constant utility. Various studies point to the advantages and disadvantages of these principles and also examine some additional loading forms-semi-variance, skewness, etc. (e.g., BüHLMANN [1970], Benktander [1971], Berger [1972], Burness [1972], Berliner [1974], Berliner and Benktander [1976], Bohman [1976], Cooper [1974], GERBER [1975] and others). Despite different preferences in choosing the appropriate loading calculation principle, all seem to agree that the risk loading must be positive, since, otherwise, the firm would just have to wait for its ruin, that is bound to come sooner or later, according to risk theory.

The purpose of this article is to re-examine the appropriate principle of premium calculation in light of the recent developments in the theory of finance and especially in the theory of capital market equilibrium. These developments may suggest a new point of view and raise a few questions regarding the loading rules.

* Senior Lecturer at the Faculty of Management, Tel Aviv University, Israel, and Academic Director, Erhard Center for Higher Studies and Research in Insurance, Tel Aviv University, Israel. The author wishes to acknowledge the very helpful discussions with Dr. B. Berliner on an earlier draft of this paper and the many remarks of the participants of the 14th ASTIN Colloquium in Taormina, October 1978. 
The first question is related to whether or not, and how, investment income should be considered in premium calculation ${ }^{1}$ ). Some insurers and insurance regulators tend to disregard investment income altogether. They misinterpret, perhaps, earlier models in risk theory which concentrated on the insurance portfolio in isolation and disregarded the investments merely for the sake of simplicity. Other insurers, and especially in certain lines, deduct investment income through the calculation of the expected present value of the relevant cash flows (claims and expenses). This paper suggests that investment income should be considered in ratemaking, either through a present value calculation, or through a negative loading on expected claims.

Another problem which can be solved with the use of financial theory is related to the appropriate measurement of risk for ratemaking purposes. It is suggested that the traditional measures of riskiness of an individual risk (standard deviation, variance, etc.) be replaced by the "systematic" element of the variance and that the risk loading be proportional to this element.

It will be shown that, since the profit of the insurer is derived from both underwriting and investment incomes, the insurer might, under certain circumstances, even be willing to lose on his underwriting activities. The appropriate loading on the expected pure claims may therefore be negative, and this may offer a theoretical explanation for the willingness of some insurers to under-rate ${ }^{2}$ ). The exact conditions for a negative loading will be studied later and an explicit expression for the profit (loss) will be presented. And finally, it is suggested that risk loadings should be determined by capital market equilibrium and must therefore be objective and uniform for all insurers.

The main argument in the following analysis can be explained by viewing a very simple example: Assume an investment company which raises funds through the sale of bonds (debt) and invests its capital plus the external funds in an assets portfolio. The required return on the shareholder's investment reflects the risks of the investment portfolio and the financial leverage (debt) used. Notice that the shareholders derive an appropriate profit after the payment of a positive interest on the firm's debt. Now assume an insurer is similar to the investment company, except that it raises the additional funds as a by-product of the sale of insurance contracts, rather than through the use of regular debt instruments. According to Quirin and Waters [1975], this is analogous to a firm which charges a positive interest rate from its creditors, rather than paying them for the use of their money. A positive underwriting profit on the insurance portfolio would mean that the insurer

1) This topic has attracted many economists and actuaries. A discussion and references to some sources may be found in BIGER and Kahane [1978], PyLe [1971], Quirin and WATERS [1975] or in a book by CoOPER [1974].

2) The traditional explanations for underrating are related to the attempt to preserve long-term connections with insureds, or to the lack of knowledge and experience (see BenkTANDER [1971]). 
makes a higher overall rate of profit than the investment company. Although the analogy is imperfect and very simplistic it may still demonstrate that consistent underwriting profits violate capital market equilibrium.

Section 2 summarizes the developments in financial literature and the riskreturn relationships in capital market equilibrium. This will be used in Section 3 to analyze the treatment of investment income in ratemaking and the implications of the financial theory for the measurement of underwriting risks and the loading factor to be used in ratemaking. Some reservations and a few concluding remarks are summarized in Section 4.

\section{RISK RETURN RELATIONSHIPS AND CAPITAL MARKET EQUILIBRIUM}

Assume that the insurance company competes for investors' funds in the capital market. The firms' profits must therefore compensate the existing and potential shareholders for the risks they assume through their investment. The insurers' profitability is affected by the premium formula, and thus the relationship between the required expected return and the risk level on the insurer's shares may serve as a key to the ratemaking formula (BoRCH [1974, ch. 22]).

Fairly recent developments in financial theory suggest that exact relationships between the expected return and the risk must prevail in market's equilibrium. A brief summary of these developments follows prior to the discussion of the implications for ratemaking.

\section{Risk and Diversification}

The basic idea in portfolio theory, which has been suggested by the pioneering work of Markowitz [1952], is imbedded in the mathematical properties of the standard deviation. I.e., the standard deviation of a linear combination of stochastic variables is typically lower than the weighted sum of the individual standard deviations. Each individual risk is represented by a stochastic variable, which is assumed to be fully characterized by its expected value and standard deviation ${ }^{3}$ ). The expected value is taken as a measure of profitability, while the standard deviation is used as a measure of the risk. It can easily be seen that there would generally be some gain from holding diversified portfolios, since the standard deviation of the portfolio will be lower (i.e. less "risky") than that of an undiversified portfolio.

This can be demonstrated by considering two securities $A$ and $B$ (see fig. 1). All portfolios obtained by holding these securities in varying proportions are represented by a curve $A P B$. The nature of this curve depends on the correlation between the random variables $A$ and $B$. In the extreme case, where the securities are perfectly positively correlated, there would be no gain from

3) See a short discussion in the concluding remarks. 
diversification $(A Q B$ in fig. 1). In the other extreme case, where all securities are perfectly negatively correlated, the investor would even be able to construct a portfolio with a positive expected return and zero standard deviation (i.e., a risk-free portfolio ( $R$ in fig. 1$)$ ), although it is composed of individual risky securities.

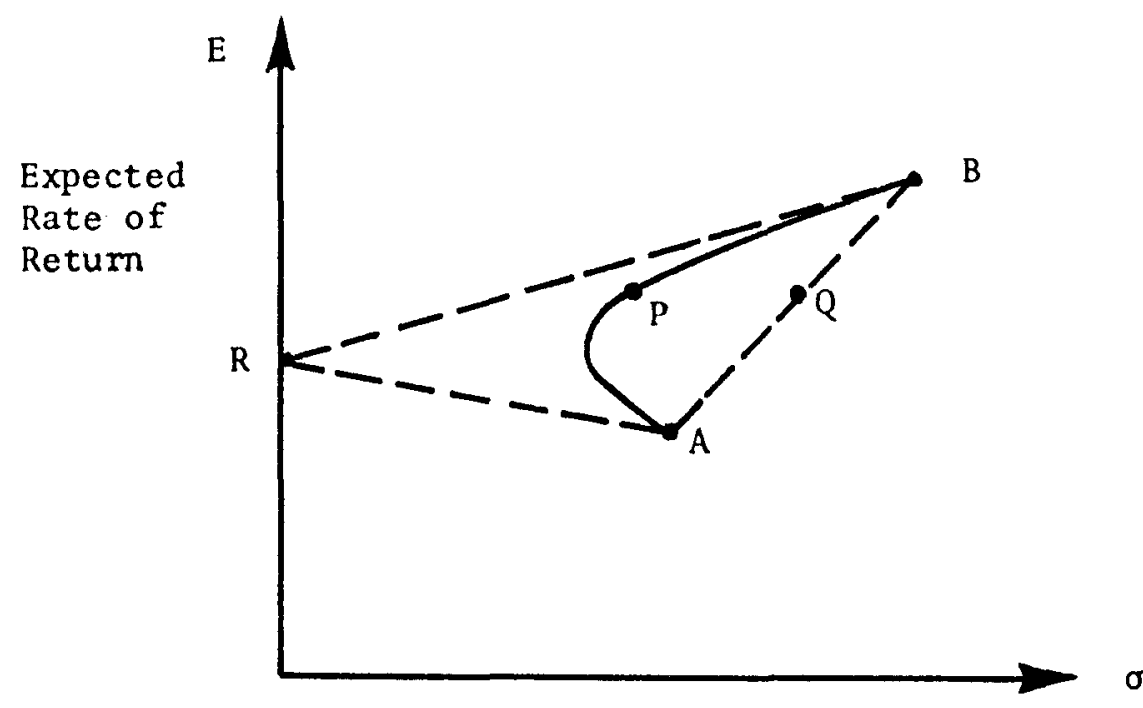

\section{Standard Deviation of Rate of Return (=Risk)}

Fig. 1. The Effects of Diversification on the Portfolio's Expected Return and Risk.

\section{Efficiency Frontier}

Identifying the optimal portfolio is clearly not an easy task, since an infinite number of combinations of each pair of securities must be examined. The first step in the optimization is to calculate the efficient portfolio, which has the minimal standard deviation for a given level of expected value. This can be accomplished quite efficiently using the Quadratic Programming Technique (MARKowitz [1952]). Repeating the same process for all levels of expected value creates the efficiency frontier which is the locus of all portfolios having the lowest standard deviation at each level of expected value (curve $D E F$ in fig. 2).

Knowing the efficiency frontier, the main problem is to select the optimal portfolio on that frontier. The traditional economic solution is based on the introduction of a set of indifference curves which represent the subjective trade-off between risk (standard deviation) and profitability (expected return). The optimal portfolio would be obtained at the tangency point between the 


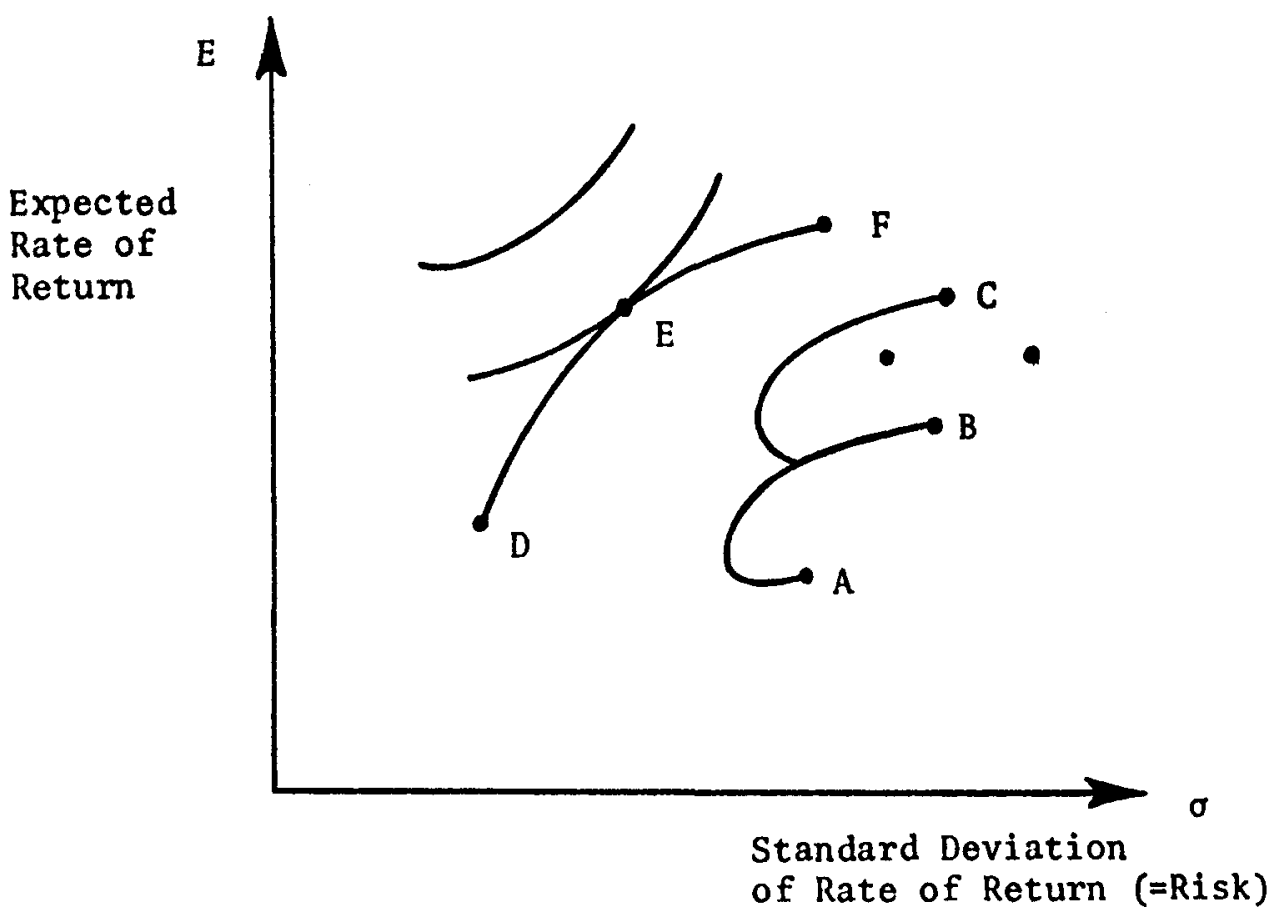

Fig. 2. Efficiency Frontier and the Optimal Portfolio.

highest possible indifference curve and the efficiency frontier (point $E$ in fig. 2). This solution depends on the individual's subjective attitude toward risk reflected by the indifference curves and assumes a full knowledge of individual utilities.

\section{The Capital Assets Pricing Model (CAPM)}

The $C A P M$ offers a new solution which does not depend on the individual's preferences and which is uniform for all investors. Its main assumption is the existence of a perfect capital market (i.e., there is a uniform interest rate at which each investor can borrow or lend any amount of money with no other transactions costs). The introduction of this interest rate, which is a risk-free security $\left(R_{f}\right)$, causes dramatic changes in the efficiency frontier; combining a risky security, or portfolio, $A$ with the risk-free security $R_{f}$ will generate portfolios on the straight line $R_{f} A$ (see fig. 3 ). The best combinations will lie on the ray $R_{f} M$ which is tangent to the original efficiency frontier at $M$. Being on the section $R_{f} M$ means that the investor lends part of his initial capital (purchases risk-free bonds). A portfolio represented by a point on ray $R_{f} M$ but to the right of $M$ is obtained by borrowing money at the risk-free rate and investing the capital and the borrowed funds in the risky 
portfolio $M$ (i.e., by using "financial leverage"). The optimal portfolio is selected in two isolated stages. The first consists of finding the portfolio $M$ of risky securities. In the second stage the desired mix of this portfolio with the risk-free asset is selected according to the tangency of $R_{f} M$ to the indifference curves.

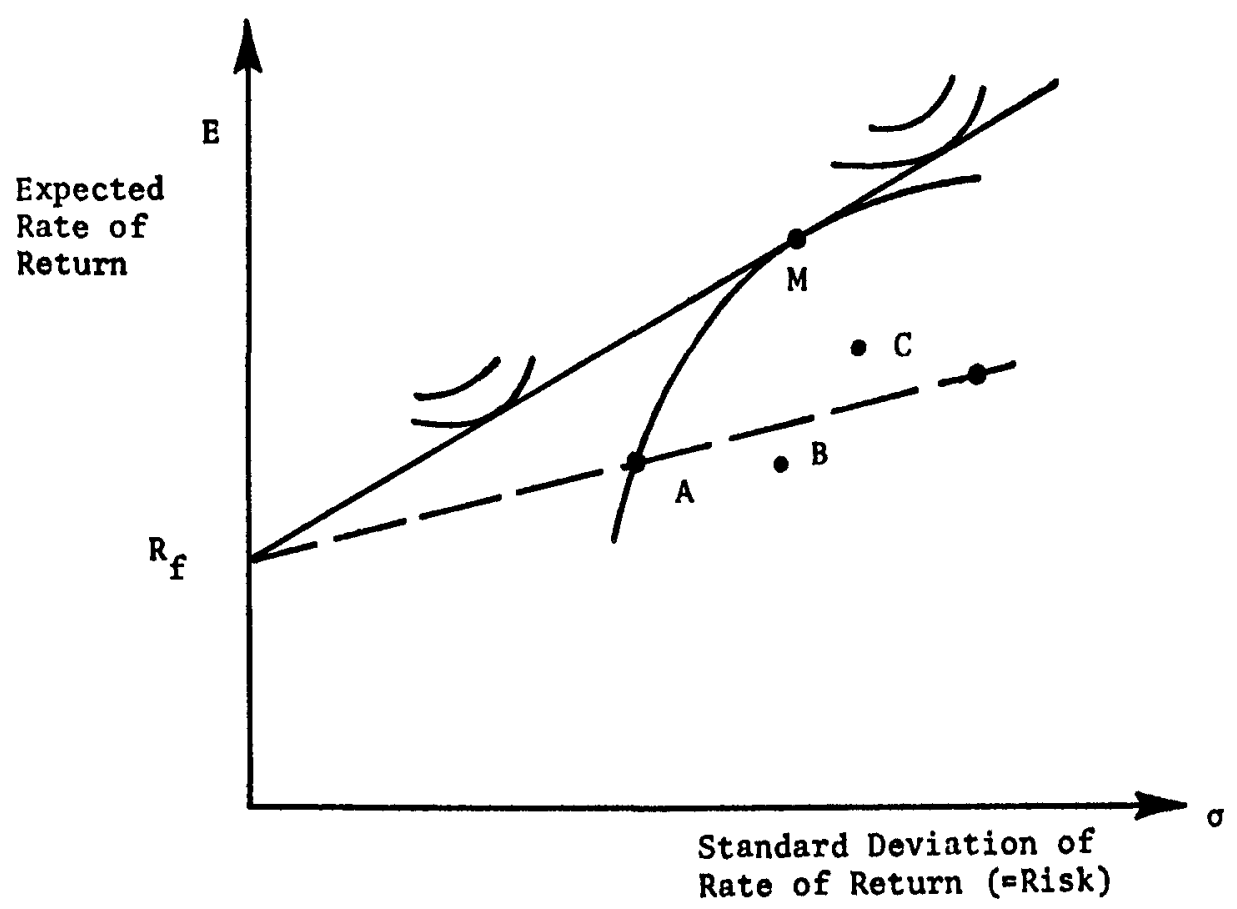

Fig. 3. Capital Asstes Pricing Model.

The next step in the development of the $C A P M$ is based on the assumption that all investors have the same expectations concerning the means, standard deviations and covariances between all securities. Under a model of full agreement, all investors must hold the same portfolio composition of risky securities (point $M$ ). This portfolio is composed of all the risky ventures and is called the "market line" portfolio. The combinations of this portfolio with the risk-free interest rate, lie on a straight line called the "market line" which represents the risk-return relationship for all portfolios in the market. It is impossible to create a portfolio with a better performance which would be represented by a point above this capital market line. Any portfolio below this line would be inferior. The equation for the capital market line is

$$
E_{p}=R_{f}+\frac{E_{m}-R_{f}}{\sigma_{m}} \sigma_{p},
$$


where $E$ and $\sigma$ denote expected value and standard deviation, respectively, and the subscripts $p$ and $m$ denote a portfolio and the market portfolio, respectively (Sharpe [1964], Lintner [1965], Mossin [1966]).

Equation (1) represents the objective risk-return relationship for a portfolio in market equilibrium and can be interpreted as follows: The expected return on any investment portfolio equals the risk-free rate of interest plus a risk loading which is proportional to the standard deviation of the portfolio.

Under the CAPM, the appropriate risk measure for a portfolio of securities is the standard deviation and not its variance. This result stems from the basic assumption of the model and therefore cannot be used as an argument against the use of a risk loading proportional to the variance, which is recommended by some of the leading authorities in the Collective Risk Theory (Bühlmann [1970], Berliner [1974], Bohman [1976], etc.).

\section{Risk-Return Relationship for an Individual Risk}

The capital market line is obtained through the holding of a combination of securities which are typically below it (like points $A, B, C$, in fig. 3). What is the appropriate risk-return relationship for the individual security? Further analysis of the $C A P M$ showed that the expected return of each individual investment under equilibrium must satisfy the following equation

$$
E_{t}=R_{f}+\frac{E_{m}-R_{f}}{\sigma_{m}^{2}} \sigma_{i m},
$$

where the $\sigma_{i m}$ represents the covariance between the return on security $i$ and the return on the market portfolio (The proof for these relationships is given by Sharpe [1970, pp. 86-90]). Equation (2) means that the expected return on the individual security equals the return on the risk-free asset plus a proportional risk loading. Unlike the relationship for a portfolio (equation (1)), the risk for an individual security is measured by $\sigma_{i m}$, the covariance of the return on the security and the market portfolio. This suggests a new measure for the risk level of an individual security-the systematic risk element. A variation of this term, namely, $\sigma_{i m} / \sigma_{m}^{2}$, is often used in financial literature for the same purpose and is called the "beta" coefficient.

The risk for an individual security, unlike the measure of risk for a portfolio (collective risk), is not measured by its standard deviation or variance. The full variance of the return on each security is split into two components: the systematic risk (representing the correlation with the market portfolio), and a non-systematic element (representing random fluctuations or noise). This is demonstrated by fig. 4, which shows the return on a hypothetical security $i$ and the return on the market portfolio. The dots on this graph represent individual observations (periodic observations). The systematic element is captured by the slope of the regression line. The vertical deviations 


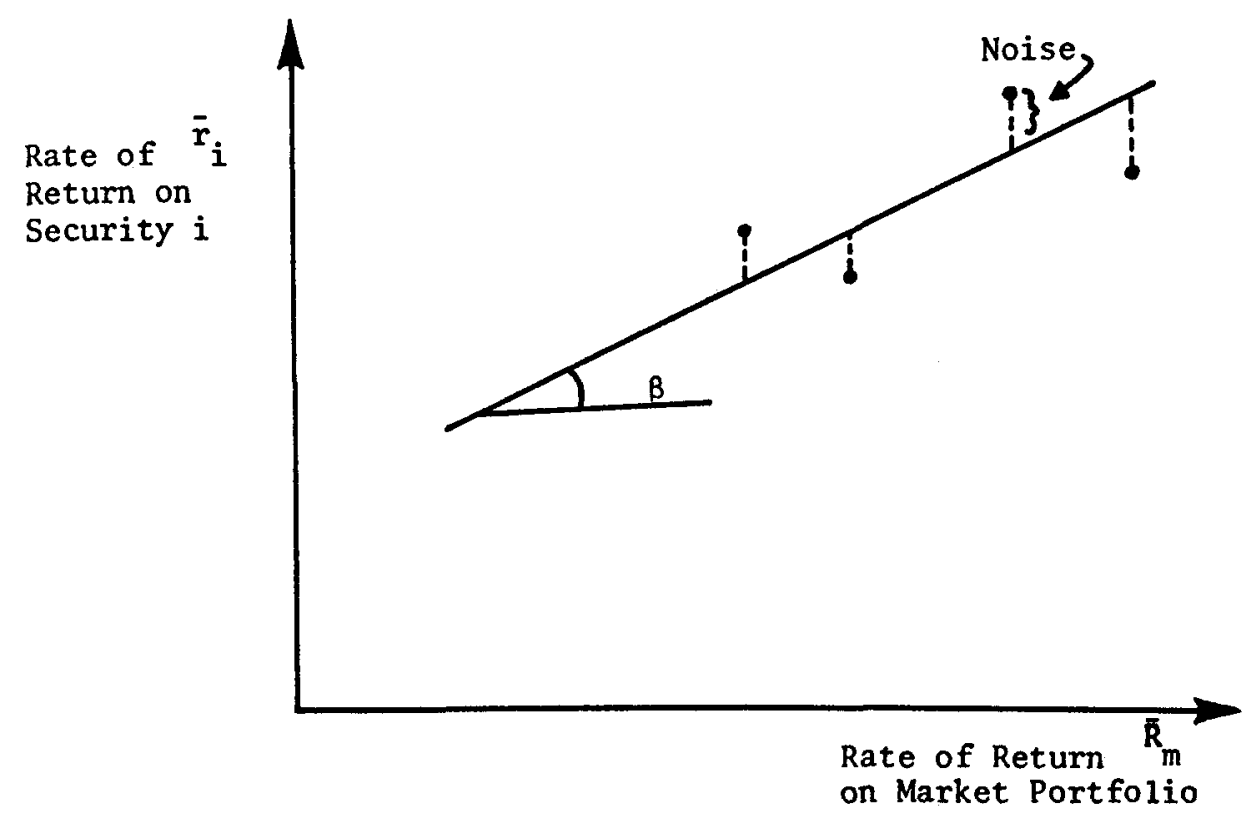

Fig. 4. Systematic and Non-Systematic Risk.

of the observed return from its conditional expected value represent a random noise.

The non-systematic element (the "noise") is excluded from the measurement of risk because it can be diversified away and eliminated to a great extent by holding appropriately diversified portfolios ${ }^{4}$ ). This results from the assumption that the random fluctuations of securities $i$ and $j$ are uncorrelated.

The return on securities fluctuates. Despite these fluctuations some securities may be regarded as risk-free where their rates of return have no consistent relationships with those of the market portfolio. In such a case their expected return must equal the risk-free rate of interest. Such securities are represented by lines with zero slope in fig. 5 . Other securities may be represented by a slope of unity. Holding such securities has an effect similar to the holding of the market portfolio itself (despite their higher variance caused by random noise). Securities having slopes steeper than unity are "aggressive", i.e., they augment the fluctuation of the market and are therefore more risky than the market portfolio. Some securities may even have negative slopes, which means that they behave counter to the market portfolio. The expected return on these securities would be lower than the risk-free rate of interest since they have a risk reduction effect in a portfolio context.

4) See a quite similar idea in BERLINER [1974]. 


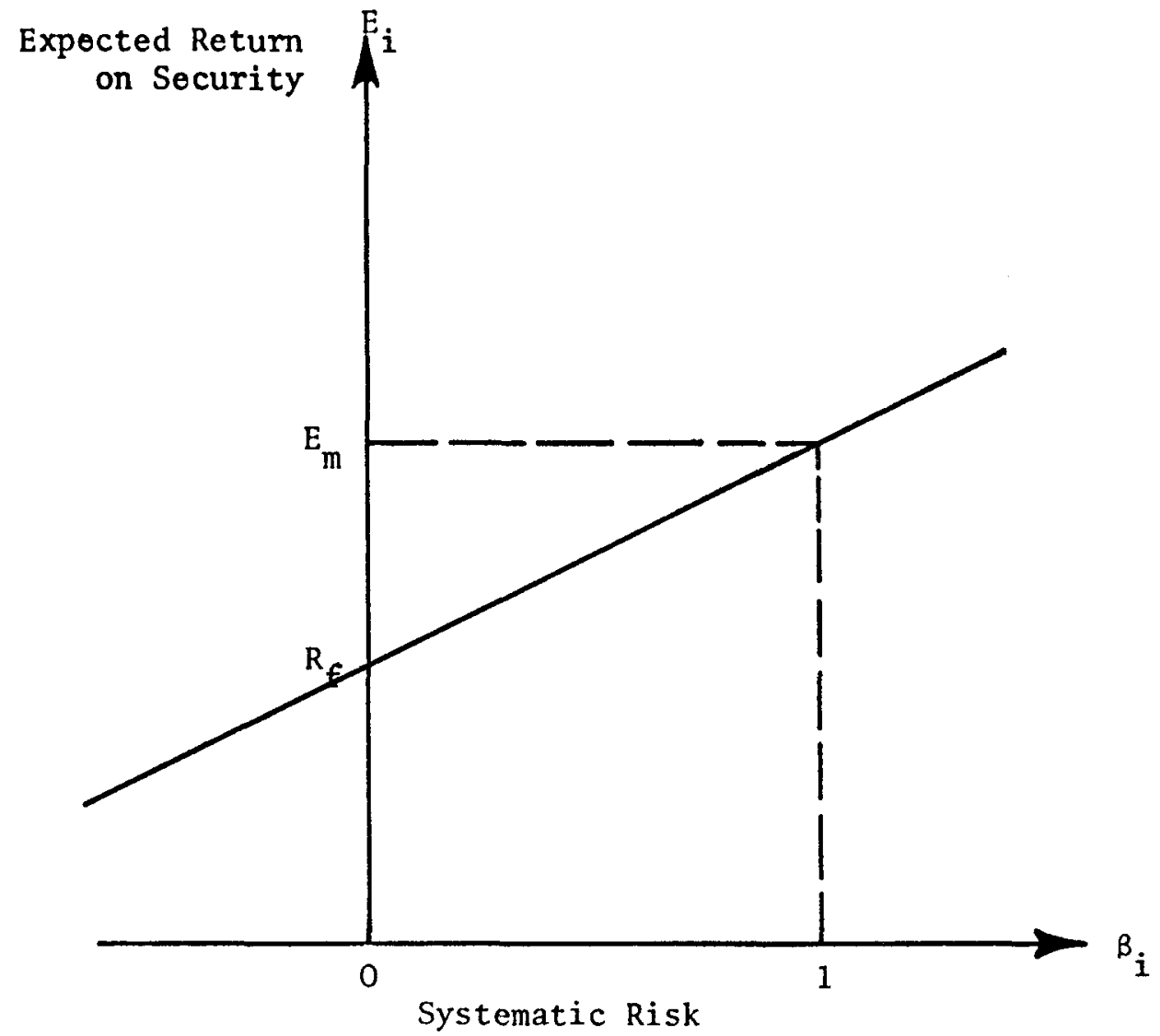

Fig. 5. The Risk-Return Relationship for Individual Risks.

\section{IMPLICATIONS FOR INSURANCE RATEMAKING}

The $C A P M$ is obviously an over-simplified representation of financial markets in the real world. The model rests on the assumption that a security is completely described by a stationary probability distribution and that only the first two moments of the distribution are relevant. In addition, the model assumes uniform information among investors, identical investment planning horizons, and perfect capital markets with a risk-free rate of interest. Despite the over-simplifications, the model seems to capture some of the essential elements in real situations and has demonstrated a fairly good explanatory power in empirical tests ${ }^{5}$ ). Unfortunately, this model has hardly received the attention it deserves in actuarial literature. Among the few exceptions are the works by Borch [1974, ch. 9, 21, 22] and by QUIRIN ET AL. [1974].

5) There are a great number of empirical tests for the validity of the $C A P M$. A review of some of the tests can be found in Modigliani and PoGUe [1974]. 
The potential of the CAPM for the analysis of the ratemaking issue is quite obvious. According to the $C A P M$, there should be an objective market price per unit of risk. This may suggest that the insurance risk loadings must be determined objectively, rather than through subjective considerations of the insurance company. It means that the loading should not depend on management attitude toward risk (i.e., its utility function). Moreover, the $C A P M$ may be used to find the exact parameters for the risk loading.

The profit of the insurer is derived from two sources: its underwriting profits and its investment income. Thus, the ratemaking problem should be analyzed by considering the two income sources simultaneously. It will be shown that previous studies which simplified the analysis by examining the insurance portfolio in isolation (e.g., BENKTANDER [1971], BüHLMANN [1970]) offered only a partial solution for the ratemaking problem.

Assume that the firm has $m$ insurance activities (policies or lines). The firm collects $\$ X_{i}$ in premiums for contract $i$ and expects to make an underwriting loss (profit) of $X_{i} \tilde{r}_{i}$ dollars. $\tilde{r}_{i}$ is a stochastic variable representing the rate of underwriting loss in this line (a negative value will denote profit). The stochastic variables are clearly affected by the ratemaking formula in use (since it determines the expected rate of profit or loss through the profit loading).

Assume that the insurer holds an investment portfolio composed of $n$ securities (assets). The amount invested in activity $i$ is $\$ X_{i}(i=m+1, \ldots$, $m+n)$, and the rate of return on this activity is a stochastic variable $\tilde{r}_{i}$. The total profit of the firm, $\widetilde{Y}$, is

$$
Y=\sum_{i=m+1}^{m+n} X_{1} \tilde{r}_{i}-\sum_{i=1}^{m} X_{i} \tilde{r}_{i}
$$

where the two summations in the right-hand term express the aggregate investment profit and the total underwriting loss (profit), respectively. Equation (3) can be expressed in terms of rate of return on equity, $\tilde{r}_{y}$, by dividing both sides of the equation by the equity capital $K$

$$
\tilde{r}_{y} \equiv \frac{Y}{K}=\sum_{i=m+1}^{m+n} \frac{X_{i}}{K} \tilde{r}_{i}-\sum_{i=1}^{m} \frac{X_{i}}{K} \tilde{r}_{i} .
$$

Let $x_{i}=\frac{X_{i}}{K}$ denote the premiums and investments relative to the capital. A subscript $j$ can be added to the elements of the equation in order to relate it to a certain insurance company $j$

$$
\tilde{r}_{y j}=\sum_{i=m+1}^{m+n} x_{i j} \tilde{r}_{i}-\sum_{i=1}^{m} x_{i j} \tilde{r}_{i} .
$$

Note that $r_{i}$ are assumed to be identical for all companies in the market. 
Now make the brave assumption that the accounting rate of return on the firm's equity is equal to the market rate of return on the firm's shares ${ }^{6}$ ). Under this assumption, equation (5) also reflects the return on the firm's shares. The $C A P M$ suggests that the expected return on firm $j$ shares is related to its systematic risk $\beta_{j}$ as follows

$$
E\left(\tilde{r}_{y j}\right)=R_{f}+\left(E_{m}-R_{f}\right) \beta_{j} .
$$

Taking the expected value of equation (5) and substituting into (6) yields (7) $\quad E\left(\tilde{r}_{y j}\right)=\sum_{i=m+1}^{m+n} X_{i j} E\left(\tilde{r}_{i}\right)-\sum_{i=1}^{m} X_{i j} E\left(\tilde{r}_{i}\right)=R_{f}+\beta_{j}\left[E_{m}-R_{f}\right]$.

Note that the systematic risk of a portfolio is a linear combination of the systematic risk elements of its components ${ }^{7}$ ). Therefore, the systematic risk of the insurance firm $j$ is a weighted average of the systematic risk of all underwriting and investment activities, that is,

$$
\beta_{j}=\sum_{i=m+1}^{m+n} x_{i j} \beta_{i}-\sum_{i=1}^{m} x_{i j} \beta_{i}
$$

Substituting equation (8) into (7) and eliminating the subscript $j$ for the simplicity of notation yields:

$$
\text { (9) } \underset{i=m+1}{\sum} x_{i} E\left(\tilde{r}_{i}\right)-\sum_{i=1}^{m} x_{i} E\left(\tilde{r}_{i}\right)=R_{f}+\left[\sum_{i=m+1}^{m+n} x_{i} \beta_{i}-\sum_{i=1}^{m} x_{i} \beta_{i}\right]\left[E_{m}-R_{f}\right]
$$

Since investment activities obey the same capital market equilibrium relationships, the expected return on every investment satisfies the equation

$$
E\left(\tilde{r}_{i}\right)=R_{f}+\beta_{i}\left(E_{m}-R_{f}\right) \quad i=m+1, \ldots, m+n,
$$

and the return on the entire investment portfolio is

$$
\sum_{i=m+1}^{m+n} x_{i} E\left(\tilde{r}_{i}\right)=\sum_{i=m+1}^{m+n} R_{f} x_{i}+\sum_{i=m+1}^{m+n} x_{i} \beta_{i}\left(E_{m}-R_{f}\right) \text {. }
$$

Subtracting (11) from (9) gives the expected underwriting profit which preserves the capital market equilibrium

$$
-\sum_{i=1}^{m} x_{i} E\left(\tilde{r}_{i}\right)=R_{f}\left(1-\sum_{i=m+1}^{m+n} x_{i}\right)-\sum_{i=1}^{m} x_{i} \beta_{i}\left(E_{m}-R_{f}\right) .
$$

$\left.{ }^{6}\right)$ The problem of consistency between accounting and market data, and especially the relationship between accounting and market betas, is studied in excellent papers by Beaver and Manegold [1975] and by Beaver, Kettler and Scholes [1970]. These papers give references to many earlier works on the subject.

$\left.{ }^{7}\right)$ Assume a portfolio $z$ consisting of a linear combination of stochastic variables $x$ and $y . \tilde{z}=\tilde{a} x+b \tilde{y}$. The systematic risk of this portfolio (where $\tilde{m}$ denotes the return on the market portfolio) is

$$
\begin{aligned}
\beta_{z} & \equiv \operatorname{cov}(\tilde{z}, \tilde{m}) / \operatorname{var}(\tilde{m})=[1 / \operatorname{var}(\tilde{m})] \cdot \operatorname{cov}[a \tilde{x}+b \tilde{y}, \tilde{m})= \\
& =[1 / \operatorname{var}(\tilde{m})] \cdot[a \cdot \operatorname{cov}(\tilde{x}, \tilde{m})+b \cdot \operatorname{cov}(\tilde{y}, \tilde{m})]=a \cdot \beta_{x}+b \cdot \beta_{y} .
\end{aligned}
$$


Assuming that each dollar of premium in insurance activity $i$ generates $g_{i}$ dollars of investment, the insurer's balance sheet equality (i.e., the requirement that assets equal the equity plus liabilities) is expressed as

$$
\sum_{i=m+1}^{m+n} x_{i}=1+\sum_{i=1}^{m} x_{i} g_{i}
$$

Substituting (13) into (12) and rearranging gives

$$
\sum_{i=1}^{m} x_{i} E\left(\tilde{r}_{i}\right)=R_{f} \sum_{i=1}^{m} x_{i} g_{i}+\sum_{i=1}^{m} x_{i} \beta_{i}\left[E_{m}-R_{f}\right]
$$

This equation does not lead to a clear-cut statement about the expected rate of underwriting loss on each individual insurance activity. Given all $\beta_{i}, E_{m}, R_{f}$ and the values of $x_{i}$, the equation is insufficient to determine a single set of $E\left(\tilde{r}_{i}\right)(i=1, \ldots, m)$ and there may be a large number of vectors that satisfy it (BIGER and Kahane [1978]). However, one possible solution may be of special interest, since it resembles the CAPM relationship

$$
E\left(\tilde{r}_{i}\right)=R_{f} g_{i}+\beta_{i}\left[E_{m}-R_{f}\right], \quad(i=1, \ldots, m) .
$$

That is, on the average, the firm would be willing to lose on insurance activity $i$ as much as $g_{i}$ times the risk-free rate, plus a risk loading proportional to its systematic risk.

\section{The Investment Income in Ratemaking}

The intuitive solution in equation (15) is attractive, since it may have an interesting interpretation regarding the treatment of investment income in the ratemaking formula. The normative question of whether or not investment income should be considered in ratemaking was extensively discussed in the literature. However, this problem has seldom been examined under capital market equilibrium, and even in these cases it was studied under the simplified model where all insurance activities were aggregated and only one or two assets were assumed (Pyle [1971], Quirin and Waters [1975]). According to equation (15), there is a negative loading $R_{f} g_{i}$ (recall that $E\left(\tilde{r}_{i}\right)$ represents expected underwriting loss) which represents the investment income and is indirectly generated through the insurance activity $i$.

Under the simplifying assumption made, the deduction should be proportional to an approximated value $g_{i}$, the funds generating coefficient. For example, if the activity generates one investment dollar for each dollar of premium but creates no systematic risk, the firm may be willing to underwrite this activity for an expected underwriting loss equivalent to the risk-free rate! On a line which generates more than one dollar of investments for each dollar of premiums (e.g., liability insurance) the firm is willing to lose even more.

A more accurate solution would probably be to deduct the investment 
income through the calculation of the present value of claim payment (similarly to the calculation of life insurance premiums). Note that this negative loading is proportional to the risk-free rate of interest, although the firm invests in a combination of risky assets. The investment risk is ignored in rate-making decision since it is accounted for by the risk premium element which is imbedded in the expected return on each risky asset, under capital market equilibrium.

\section{Risk Loading in Ratemaking}

The expected underwriting loss in equation (15) is also a function of the "risk" of the specific insurance contract. Equation (15) therefore may serve as a guide in determining the risk loading. Since the analysis concentrated on underwriting losses, a project with a positive beta has the desirable riskreduction properties. Therefore, a positive beta would justify additional underwriting loss (over the negative investment income loading).

The risk loading is proportional to the systematic element of risk, beta, that reflects the contribution of an activity to the market portfolio. This means that the underwriting loss (profit) on an activity may fluctuate dramatically around its expected value (i.e., high variance) but nevertheless may be regarded as riskless by the shareholders of the firm. The risk loading is proportional to the beta, according to the objective price of a unit of risk. This price factor is given by the difference between the expected return on a market portfolio and the return on the riskless interest rate. This price is uniform for all investors.

Preliminary findings presented in a recent paper by BIGER and KAHANE [1978] suggest that underwriting profits are uncorrelated with the rate of return on the market portfolio (i.e., underwriting activities have no systematic risk). Thus, according to equation (15), the average underwriting losses should be approximately equivalent to the risk-free rate of interest ( $g_{i}$ is commonly close to 1), while for the liability insurance lines, which typically generate more funds because of the long claims settlement period (reflected by larger $\left.g_{i}\right)$, the losses must be even higher.

Rough empirical evidence in support of the ratemaking formula suggested in this paper can be obtained from aggregate statistical data of the insurance industry. Although the ratemaking formulas approved by regulators in most countries include a positive profit loading on net premiums, insurers often report underwriting losses. In view of the underwriting losses which insurers do complain about, and noting that the losses typically fluctuate in the range around the level of the risk-free rate of interest, the loading formula suggested here has some explanatory power. It appears as if competition has forced the rates to reach their equilibrium level, despite the regulatory formula. 


\section{CONCLUDING REMARKS}

This paper examined some of the implications of recent developments in the financial literature and capital market equilibrium theory for the insurance ratemaking problem. In an early and almost unique study of this problem, Borch [1974, ch. 9] stated that no pareto optimal equilibrium can exist in (re)insurance market. We did not obtain a unique solution either, but we presented a possible solution that has a great intuitive appeal.

The ratemaking formula which is suggested in this paper has at least two types of loadings (on top of the "expected gross claims"): (a) a loading to reflect the investment income; and (b) a risk loading.

\section{The Role of Investment Income}

Earlier studies in risk theory concentrated on the statistical nature of the claims process in isolation. This simplifying assumption led, unfortunately, to the incomplete solution which ignored the ability of the firm to obtain an investment income as a result of its underwriting activity. The ratemaking formula suggested here includes a negative loading which is proportional to the amount of investment generated by the insurance activity. The relevant rate of interest is the risk-free rate of interest (even though the funds are typically invested in risky assets).

This may be considered an approximation to the deduction of the investment income through the calculation of present values. Such an approach is taken in the actuarial calculation of life insurance premiums but is often disregarded in non-life insurance.

\section{Risk Loading}

A second element in the ratemaking formula is a loading for the risk of the individual activity. Two new concepts are introduced: First, the risk level of an individual risk is measured by the systematic risk ("beta") rather than by the variance, standard deviation or other traditional measures. Secondly, most authorities in the field of risk theory concentrate on "internal" factors to determine the correct loading--those related to the nature of the individual activity or of the firm (e.g., management utility). It is argued in this paper that the appropriate loading is determined objectively, according to the market's price of a unit of risk, rather than through the subjective decision of the firm. Thus, the traditional thought that a small firm is "punished" by having to charge a higher loading (BENkTANDER [1971]) should be re-examined ${ }^{8}$ ).

8) Theoretically, the availability of reinsurance enables the small firms to transfer the excessive risks, as long as there is no discrimination in reinsurance rates. 


\section{Limitations}

Despite its simplified assumption, the model sheds some light on the ratemaking formula problem. Some reservations and suggestions for future studies seem, however, to be required.

(a) The model is based on the assumption that insurers and investors know the correct parameters of the relevant distributions. The risk element resulting from statistical errors and incorrect (biased) estimation of the parameters has not been discussed here. Such an element may justify a special risk loading. Similar recognition should be given to the risk originated by non-stationary distributions.

(b) The level of aggregation affects the risk measure. The term "insurance activity" can be used in a narrow meaning (individual policy) or a broader sense (an insurance line). At higher levels of aggregation, the systematic risk approaches the standard deviation (since 'noise' is eliminated through diversification). Thus, when dealing with aggregated lines, the difference between the "beta loading" and the traditional loading, which is proportional to the standard deviation or variance, is very limited indeed ${ }^{\mathbf{9}}$ ).

(c) All distributions were assumed to be characterized by the first two moments. This makes the model acceptable only for certain utility assumptions. It is not inevitable that loading factors which are related to higher moments should be analyzed under more sophisticated models. Thus, measures of asymmetry, like the skewness and semi-variance, may be needed in a loading formula (especially for risks with catastrophic nature-which are represented by extremely skewed distributions). Another shortcoming of the model is its limitation to a single period analysis so that it cannot handle diversification over a multi-period horizon-which may be needed for the risks with catastrophic nature.

(d) The analysis ignored the problem of inflation and growth. All parameters were assumed stable and in real terms. Non-zero inflation, for example, may cause some problems since riskless assets may become risky in real terms, and this may create difficulties with the CAPM. Also, since investment income often does not keep up with inflation, there may be a need for another element of positive loading. The problem of inflation is only partially handled in the model through the determination of the parameters.

The model suggested in this paper cannot be regarded as the final answer to the ratemaking problem in practice. There is still much room for further improvements through the development of models with more relaxed assumptions. Some adjustments will probably improve the explanatory power of the model. Among these, a possible suggestion is the analysis of the case

$\left.{ }^{9}\right)$ Some empirical evidence shows that the rate of return on shares in the stock market is related to both their "betas" and the standard deviations. (See a summary in Modigliani and Pogue [1974]). 
where investors have different planning horizons and may differ in their anticipation of the prospects of various securities. In addition, it would be worthwhile to examine the effects of other imperfections in the capital and reinsurance markets and the effects of possible differences between accounting and market data.

Despite these obvious shortcomings of the model, it contributes to a better understanding of and a new approach to the calculation of insurance rates.

\section{REFERENCES}

Beard, R. E., T. Pentikainen, and E. Pesonen. (1969). Risk Theory, Methuen \&Co., London.

Beaver, W., P. Kettler, and M. Scholes. (1970). The Association between MarketDetermined and Accounting-Determined Risk Measures, Accounting Review, 654-682.

Beaver, W. and J. Manegold. (1975). The Association Between Market-Determined and Accounting-Determined Measures of Systematic Risk: Some Further Evidence, Journal of Financial and Quantitative Analysis, 10, 231-284.

Benktander, G. (1971). Some Aspects of Reinsurance Profits and Loadings, The ASTIN Bulletin, 5, 314-327.

Berger, G. (1972). An Attempt on the Subject: Profit Goal and Security Loadings in Risk Insurance, Transactions of the 19th International Congress of Actuaries, 4, 595-603.

Berliner, B. (1974). Some Thoughts on (Re) insurance Loadings under a Ruin Criterion, Scandinavian Actuarial Journal, 2, 76-80.

Berliner, B. (1977). A Risk Measure Alternative to the Variance, The ASTIN Bulletin, 9, 42-58.

Berliner, B. (1976). On the Choice of Risk Loadings, Transactions of the 2oth International Congress of Actuaries, Tokyo.

Biger, N. and Y. Kahane. (1978). Risk Considerations in Insurance Ratemaking, Journal of Risk and Insurance, 45, 121-131.

Bohman, H. (1976). Solvency and Profitability Standards, Scandinavian Actuarial Journal, 2, $110-113$.

Borch, K. (1974). The Mathematical Theory of Insurance, Lexington Books.

Bühlmann, H, (1970). The Mathematical Methods in Risk Theory, Berlin: Springer Verlag.

Burnens, E. (1972). Contingency Loadings in Life Insurance, Transactions of the 19th International Congress of Actuaries, 4, 621-631.

Commonwealth of Massachusetts, Division of Insurance, Rate of Return and Profit Provision in Automobile Insurance, Unpublished Memorandom, (1977).

CoOper, R. W. (1974). Investment Return and P-L Insurance Ratemaking, Homewood, Illinois, Irwin, Inc.

Gerber, H. (1974). On Additive Premium Calculation Principles, The ASTIN Bulletin, 7, $215-222$.

Kahane, Y. (1977). Ratemaking and Regulation in Property-Liability Insurance, Quarterly Review of Economics and Business, 17, 97-112.

LINTNER, J. (1965). The Valuation of Risk Assets and the Selection of Risky Investments in Stock Portfolios and Capital Budgets, The Review of Economics and Statistics, 47, 13-37.

Markowitz, H, (1952). Portfolio Selection, Journal of Finance, 7, 77-91.

Modigliani, F, and J. Pogue. (1974). An Introduction to Risk and Return: Concepts and Evidence, Financial Analysts' Journal, 68-79 and 69-85.

Mossin, J. (1966). Equilibrium in a Capital Assets Market, Econometrica, 34, 768-783.

Pyle, D. H. (1971). On the Theory of Financial Intermediation, Journal of Finance, 26, $737-747$. 
Quirin, D. G., Halpern, P. J., Kalymon, B. A., Mathewson, G. F. and W. R. Waters. (1974). Competition, Economic Efficiency and Profitability in the Canadian $P-L$ Insurance Industry, Toronto: Insurance Bureau of Canada.

Quirin, D. G. and W. R. Waters. (1975). Market Efficiency and the Cost of Capital: The Strange Case of Fire and Casualty Insurance Companies, Journal of Finance, 30, $427-45^{\circ}$.

Sharpe, W. F. (1964). Capital Asset Prices: A Theory of Market Equilibrium under Conditions of Risk, Journal of Finance, 19, 425-442.

Sharpe, W. F. (1970). Portfolio Theory and Capital Markets, New York, McGraw Hill. 